Journal of Development and Communication Studies, Vol. 6. No. 1, January - June 2019 ISSN (Online \& Print): 2305-7432.

http://www.devcomsjournalmw.org.

\title{
'LAST SEEN NOW': Explaining teenage identities and social capital on social network sites in Kenya
}

\author{
Geoffrey Serede Sikolia, Information Science Department, Kenya Methodist University, Nairobi, Kenya. Email: \\ gserede@gmail.com \&
}

Hellen K. Mberia, School of Communication and Development Studies, Jomo Kenyatta University of Agriculture and Technology, Nairobi, Kenya. Email: bellenmberia@gmail.com

\begin{abstract}
This article sought to address the gap in empirical research related to personal identity and social capital as gratification factors motivating teenage engagement on Social Network Sites (SNSs) in Kenya. We employed a mixed method research design in which Self-administered Questionnaires, Focus Group Discussions and In-depth Interviews were used in data collection. Participants were drawn from a sample of $(n=481)$ respondents from two sub-counties of Nairobi County. We focused on five popular SNSs namely, Facebook, Twitter, LinkedIn, Google+, and Pinterest. Findings revealed that personal identity and social capital significantly influenced teenagers' engagement on SNSs. Specifically, high school teenagers' engagement on SNSs was motivated by the need to bridge and maintain social capital more than bonding. We conclude that social network sites engagements among teenagers need to be harnessed for positive outcomes. Equally, we recommend positive use of SNSs in behavior change campaigns targeting teenagers.
\end{abstract}

Keywords: Social Network. Sites, Personal identity, Social capital, Uses and Gratifications, Teenagers https://dx.doi.org/10.4314/jdcs.v6i1.2

\section{Introduction}

Past studies have painted today's adolescents as "digital natives" and "millennial learners". Greenhow and Robelia (2009) have further argued that the discrepancy between adult perspectives on new media and youth's experiences are attributable to a "generational divide" between young people of the Internet generation and adults in terms of their technology skill, use, and experiences. Teenagers are thus depicted as "other" and their use of social network sites considered new. Research on teenagers' use of new media, specifically Social Network Sites (SNSs) is still emerging, with questions regarding exactly what they do on these sites, whom they interact with, and how their SNSs use relates to their other online and off-line activities still lingering (Baker \& White, 2010; Boyd \& Ellison, 2008; Subrahmanyam, Reich, Waechter \& Espinoza, 2008; Ahn, 2011). Boyd and 
Ellison (2008) have further argued that SNSs are the latest online communication tool that allows users to create a public or semi-public profile, create and view their own as well as other users' online social networks. That teenagers are connected to these global online communities is both a frightening prospect for parents and educators and an intriguing area for social science research (Ahn, 2011).

According to Ahn (2011) teenagers are a unique population of SNSs users. They are among the first to have grown up entirely surrounded by communication technologies. This group is also in a period of rapid development, growth, and maturation. Research about social media effects on youth promises to contribute significantly to the concerns of adults who mediate access to these online communities.

The Ministry of Youth Affairs (2007) in the national youth policy stated that although Kenyan youth constitute 32 percent of the population, they have remained on the periphery of the country's affairs and their status has not been accorded due recognition. Important policy documents such as Kenya Vision 2030 and the Sustainable Development Goals (SDGs) may not be achieved without incorporating the teenage youth population. The selected teenage group (14 to 19 years) is considered to be at its peak and is progressively inching closer to the employment category. Therefore, this means that there should be more focus on research targeting this particular age group. Given the growth of SNSs, and the amount of media attention that their use has garnered, "including the seemingly now obligatory scare stories involving predatory child sex offenders, identity theft, workplace usage levels, and even addiction"(Joinson, 2008: p. 1027), it is imperative that more attention be focused on teenagers' interaction with these media. Whereas Brandtzæg (2009) has argued that few attempts have been made to understand why people participate or do not participate in SNSs or online communities, the next section enumerates few studies that are related to our context.

\section{Youth culture and teenage identities}

According to Heaven and Tubridy (2007) "to be a youth is to be distinguished from the remainder of the population not just by age but by a certain level of agency; a particular relationship to the labor market; and youth-specific cultural pursuits" (p. 150). Heaven and Tubridy (2007) further argued that youth in developing countries are for the most part "excluded from the youth experience that their economies make possible in the developing world" (p. 151). The United Nations classifies a majority of youths as living in developing countries, with Africa, Latin America and the Caribbean accounting for 23 percent of the world's youth.

In Kenya, Njonjo and Mwangola (2011) describe the youth based on the following adjectives and phrases.

...the majority; fresh and dynamic; a mind-set (you are as young as you feel or think); unemployed; techno savvy; risk takers; creative, diverse and innovative; easily manipulated; lacking an identity; criminals; good social networkers; drug abusers; excluded from formal decision making processes; categorized into a poor majority and a rich minority; unreligious; transitional stage from childhood to adulthood... unsettled and constantly in transition (including when it comes to jobs, boy/girl relationships or in education). Daring because they do not have family and other life's responsibilities; desperate due to many unmet needs; generally misunderstood by the older generation and are therefore constantly viewed negatively; rowdy and often clustered as troublemakers; energetic; economically challenged; adventurous; considered immature; seen as a market by entrepreneurs; a cheap source of labor; as those who pursue instant gratification; bullies; cool; unutilized potential; needy; no interest in agriculture; vigilantes, gangs and militias; creative; chaotic; celebrities; entertaining; hard headed; children; criminals; suspects; as needing guidance and advice; manipulated. 
They are seen as a threat especially to the political elite; non-conformists; unstable; heretics; mischievous; marginalized; easily enticed; those who are not married; sexually active and morally decadent; lack financial and entrepreneurial skill; conditioned to white collar jobs than self-employment; used and abused; ignorant; fear responsibility; constant volunteers; idle; disillusioned; hopeful; frustrated; not tribal; leaders of tomorrow; conservative; balkanized; greatest consumers of foreign culture; as those who idolize celebrities and on, and on. (Pp. 13-14)

Identities structure the way a person understands themselves and their world in both descriptive and prescriptive perspectives (Heaven \& Tubridy, 2007). It is further posited that identities change according to circumstance, and to some extent, preference. This leads to a complex, often contradictory and typically deep-seated understanding of their nature and their world. Our interest was particularly on the key aspect of teenage identity. Considering the fact that the youth are described as good social networkers, it was critical that our study focuses on their motivations for Social Network Site (SNS) choice.

\section{Empirical review}

Several studies have been carried out relating the Uses and Gratifications (U\&G) theory to SNSs. In one such study, Urista, Dong and Day (2009) sought to explain why young adults used MySpace and Facebook through the U\&G theory. The exploratory study applied the focus group method to investigate how members of Facebook and MySpace used the sites to fulfill their wants and needs. This qualitative approach was used in order to provide insights into thoughts, ideas, perceptions, and attitudes of individual SNS members who used online sources to fulfill their needs and wants. Findings revealed five themes from the focus group discussions. These included: (a) efficient communication, (b) convenient communication, (c) curiosity about others, (d) popularity, and (e) relationship formation and reinforcement. The findings also suggested that an immediacy driven tendency motivated young people to use SNSs. Members used SNSs to satisfy a specific gratification that they sought. Whereas Urista, Dong, and Days' (2009) study is different from the current one, there are some parallels in relation to the research method and theoretical framework applied. The classification of young adults is also broad considering that these could be in the age category of between 15 to 24 years (UNFPA, 2011). Our study focused on high school teenagers between the ages of 14 to 19 .

In another study, Wyche, Schoenebeck and Forte (2013) examined Facebook use in Kenya, where social media participation is growing but is limited by less developed technological infrastructures and uneven access to technology. This study emphasized how the potential for ICT to support economic prosperity, education, and civic engagement had been widely discussed, but laments the scarcity of research on SNSs in such contexts. This was a qualitative study where the researchers conducted observations and interviews at Internet cafés in rural Kenya. Among the key findings of the study included the fact that participants were familiar with Facebook but there were high costs associated with Facebook access in rural Kenya. Cases of limited bandwidth and power outages were also cited as impediments to Facebook access. Though focused on a narrow aspect of SNSs, this study presents one of the first studies of SNSs use in rural and peri-urban Kenya. Whereas Wyche, Schoenebeck and Forte's (2013) study sets the stage for future research on SNSs, there is a clear gap in the relationship between theory and SNSs use. The study also fails to address a specific segment of the population, thus making it difficult to direct communication strategies aimed at segments of the population. The present study presented a different perspective to the study of urban populations' choices of SNSs by specifically targeting high school teenagers. 


\section{Scope of the study}

Geographically, the study focused on teenagers from public high schools within Dagoretti and Langata sub-counties in Nairobi County. Nairobi County comprises nine sub-counties and hosts the capital city of Kenya. According to the Kenya National Bureau of Statistics (KNBS) and ICF Macro (2010), exposure to mass media in the selected county is high (52.5 percent). The KNBS (2010) survey further indicated that Nairobi reported the highest levels of literacy (25.3 percent), secondary school attendance rates (92.9 percent), and the highest concentration of urban wealth (79 percent). Dagoretti and Langata sub-counties were selected considering the socioeconomic status represented. Langata sub-county comprises Kibera informal settlement and also consists of the higher and middle-income residential estates of Karen and Langata respectively. Dagoretti subcounty, on the other hand, comprised Kawangare informal settlement and parts of the high-income areas of Karen and Ngong. These demographic characteristics presented rich data for the study.

The Kenyan education system comprises eight years of primary school, four years of secondary school and four years of university. According to UNESCO (2006), secondary school education in Kenya lasts four years and caters for 14 to 17 year olds. It is organized into two stages of two years duration each. At the end of the course, students sit an examination administered by the Kenya National Examinations Council leading to the Kenya Certificate of Secondary Education. This examination is used for selection of students for university courses or for training in other post-secondary institutions. Additionally, each student is given a school leaving certificate, which reflects observed abilities and character development. The mode of instruction is English and thus our data collection methods were all in English.

\section{Theoretical perspectives}

Theoretically, few studies have incorporated the use of communication theory in order to understand teenage interactions with SNSs. This article is premised on the Uses and Gratifications (U\&G) theory as propounded by Blumler and Katz in 1974. The U\&G theory is based on the notion that media cannot influence an individual unless that person has some use for that media or its messages (Rubin, 2002). This marks a shift from the traditional viewpoint of "powerful-mediaeffects" theories in which an audience is depicted as passive and easily manipulated by media influences. Quan-Haase and Young (2010) have argued that in U\&G theory a key distinction is made between gratifications obtained and gratifications sought. Quan-Haase and Young (2010) drew this distinction by arguing that "gratifications obtained refer to those gratifications that audience members actually experience through the use of a particular medium" (p.352). By contrast, gratifications sought, which are often referred to as "needs' or "motives" refer to "those gratifications that audience members expect to obtain from a medium before they have actually come into contact with it" (Quan-Haase \& Young, 2010: p. 352).

In this article, we focused on the "gratifications sought" by high school teenagers in their engagement with SNSs. Dunne, Lawlor and Rowley (2010) have reinforced this by classifying gratifications sought as "communication, friending, identity creation and management, entertainment, escapism and alleviation of boredom, information search, and interaction" against gratifications obtained, which include "portrayal of one's ideal image, peer acceptance, relationship maintenance, safety from embarrassment and rejection, and engagement in playground politics" (Dunne, Lawlor \& Rowley, 2010: p. 51). Song, Larose, Eastin and Lin (2004) found seven gratification factors specific to the Internet. These are; virtual community, information seeking, aesthetic experience, monetary compensation, diversion, personal status, and relationship maintenance. From the foregoing arguments, it is quite clear that teenagers seek a variety of gratifications from SNSs and, in turn, gain different satisfactions from the same. 
The U\&G approach was propounded by Blumler and Katz in 1974. The underlying assumption is that audiences are active and they seek out that content which provides the most gratification (Fawkes \& Gregory, 2001). Fawkes and Gregory further added that "the level of gratification depends on the level of need or interest of the individual" (Fawkes \& Gregory, 2001: p. 120). According to Katz, Blumler and Gurevitch (1973-1974), the last few years have witnessed a revival of direct empirical investigation of audience uses and gratifications. Each of these studies has attempted to press towards a greater systemization of what is involved in conducting research in this field. Katz, Blumler and Gurevitch added that the U\&G approach is concerned with: "(a) the social and psychological origins of, (b) needs, which generate, (c) expectations of, (d) the mass media or other sources, which lead to, (e) different patterns of media exposure (or engagement in other activities), resulting in, (f) need gratifications and, (g) other consequences, perhaps mostly unintended ones" (p. 510). This model informed our article in the sense that, (a) teenagers have social and psychological needs, which (b) determine the gratifications sought through specific SNSs, and (c) have expectations of the different SNSs available, which (d) enables them to access social network sites, (e) and engage in different online activities, resulting in ( $\mathrm{f}$ ) gratifications obtained and, (g) other consequences (both positive and negative), mostly unintended.

\section{Personal identity}

Personal identity was a critical variable in this study considering that the importance of presenting a positive self-identity among teenagers cannot be overemphasized. Harrison and Thomas (2009) defined identity as "the way in which users develop their online profiles and lists of friends to carry out important community processes" (Harrison \& Thomas, 2009: p. 114). They further outlined aspects of identity as follows:

(a) Impression management, which is concerned with personal identity formation, (b) friendship management, which is linked to impression management in that users use publicly displayed profiles of others to choose who they would like to include as friends on their list, (c) network structure, relates to the roles that users play in the social community in which they participate, and (d) bridging of online and offline social networks, which is concerned with the degree to which the SNS becomes an integral part of the users' actual life while offline (Harrison \& Thomas, 2009: p. 114).

This is evidenced by Dunne and Lawlors' (2010) study on young people's use of online SNSs. Their study was carried out among girls aged 12 to 14 years and focused on one SNS 'Bebo'. Findings revealed an active use of Bebo for personal motives and gratifications in terms of presenting and managing a certain identity and persona in a social context. One respondent in their findings stated, "sometimes you look at people's profile pictures and go 'oh my god, what are they at'? Some of the stuff they say about themselves is exaggerated as well; they are trying to make themselves look cool" (Dunne \& Lawlor, 2010: p. 52). Chigona, Kamkwenda and Manjoo (2008) have echoed this by arguing that among the process gratifications sought by the youth include the need for image, fashion and status. We thus presented the following hypothesis.

$\mathrm{H}_{01} \quad$ There is no relationship between personal identity and choice of social network sites among high school teenagers.

\section{Social capital}

The concept of social capital draws a variety of definitions in multiple fields (Ellison, Steinfield and Lampe, 2007). Broadly though, (Ellison, Steinfield \& Lampe, 2007; Valenzuela, Park \& Kee, 2009) defined social capital as the resources accumulated through the relationships among people. This definition is reinforced by Williams (2006) who asserts that: 
It is loosely understood to operate like financial capital in that it creates more of it. However, instead of goods and services, the things being used and created are personal relationships and the benefits that come with them: Some social actors interact and form a network of individuals - a "social network"- resulting in positive affective bonds. These in turn yield positive outcomes such as emotional support or the ability to mobilize others (Williams, 2006: p. 594).

Valenzuela, Park and Kee (2009) have argued that unsafe disclosure of information, cyberbullies, addiction, risky behavior, and contact with dangerous communities are among the popular concerns raised about the use of SNSs. They further posited that "other research shows that young people are motivated to join these sites to keep strong ties with friends and to strengthen ties with new acquaintances" (Valenzuela, Park \& Kee, 2009: p. 876). This validates Williams's (2006) argument that bridging and bonding social capital could be motivating factors influencing choice of SNSs.

Putnam as cited in Williams (2006) split social capital into "bonding" and "bridging". He has argued that bridging and bonding allow for different types of social capital to result when different norms and networks are in place. According to Putnam, these two types of social capital are related but not equivalent. Bridging social capital is inclusive and occurs when individuals from different backgrounds make connections between social networks. By contrast, bonding can be exclusive. It occurs when strongly tied individuals, such as family and close friends, provide emotional or substantive support for one another (Williams, 2006). Papacharissi and Mendelson (2008) have argued that media audiences also seek to maintain social capital. They add that maintained social capital focuses on staying connected to groups from previous moments in one's life. The question though at this point is whether high school teenagers' choice of SNSs is motivated by the desire to "bridge", "bond" and "maintain" social capital. This was hypothesized as:

$\mathrm{H}_{02}$ There is no relationship between social capital and choice of social network sites among high school teenagers.

\section{Methodology}

Towards understanding motivations for engagement with SNSs among high school teenagers, this article adopted a mixed method research design. Stratified sampling was used in order to achieve adequate representation from sub samples. The study population was divided into two strata, (a) boys, and (b) girls. Considering that the population of the study was 42,531, the sample size of 385 respondents was therefore used. This figure was further over sampled in order to achieve a response rate of 80 percent thus;

Number of tools $=\underline{100} \times 385=481$

80

The study population was first stratified based on school enrollment data. Two sub-counties (Dagoretti and Langata) were then purposively selected from the strata based on the highest and lowest enrollment. Proportional allocation was used in determining the actual sample size for each stratum. Therefore 294 male respondents and 187 female respondents drawn from seventeen public high schools within Langata and Dagoretti sub counties participated in the study. Questionnaires,

FGDs, and In-depth interviews were conducted on the selected sample of the population comprising teenagers in forms two, three and four.

\section{Data collection methods}




\section{Self-administered questionnaires}

The first instrument that was used in data collection was the self-administered questionnaire. Questionnaires are considered advantageous in the sense that they are less costly and can ask more sensitive information than either type of interview, due to rapport that develops between the respondent and the survey instrument. They are also preferred because reading comprehension is higher than aural comprehension needed in an interview and can be much longer and more complex (Lee \& McKinney, 2013). Questionnaires were administered to the selected sample of 481 respondents. Considering that proportionate sampling, which included strata with sizes based on their proportion in the population (Tayie, 2005) was applied, questionnaires were distributed as follows:

The study further subdivided this sample according to the identified stratum of class. Questionnaires were distributed to a stratified random sample of forms two, three and four among public high schools in the two sub-counties. Considering that the schools were classified into three categories of boys', girls', and mixed gender, questionnaires were administered to purposively selected respondents in the three classes. The study employed the help of class teachers and class representatives to identify respondents who currently or had in the past belonged to SNSs. After these were identified in each of the three target classes, a random sample from each class was selected based on class attendance registers to participate in the study. 


\section{Focus Group Discussions (FGDs)}

Considering that a mixed methodology was used, this study employed FGDs as one of the data collection methods. Hennink, Hutter and Bailey (2011, p. 136) defined the FGD as "an interactive discussion between six to eight pre-selected participants led by a trained moderator and focusing on a specific set of issues". Three FGDs were conducted on purposively selected samples of high school teenagers in order to uncover unique perspectives on their choice of SNSs. FGDs provide an effective means to identify community norms, views and behavior (Hennink, Hutter \& Bailey, 2011). Onwuegbuzie and Collins (2007) propose six to nine participants for FGDs. They further argued that mixed method designs constitute three to six focus groups. This study employed three FGDs comprising between six to nine participants. The study employed purposive sampling in the selection of FGD participants. Participants in the FGDs were selected based on the number of SNSs they belonged to and the frequency of their SNSs use. Respondents belonging to more than three SNSs and spending more than four hours daily on SNSs participated in the study. Each FGD further comprised a participant from the three classes under focus. Considering that a majority of the respondents resided in Nairobi (46.8 per cent) and Kajiado (40.9 per cent ), respondents' residence was not used as a criterion for FGD participation. Overall, three FGDs comprising one each for boys', girls', and mixed gender schools were conducted. The FGDs commenced with the moderators introducing themselves and equally having the participants conduct brief introductions. This enabled the participants to relax. The researcher generally outlined the purpose of the FGD and assured them of confidentiality. Consent was sought from participants on whether a recorder could be used to capture the proceedings, which was unanimously accepted. The discussions proceeded with the assistance of one research assistant, who helped in the recording. Overall, the researcher made field notes and moderated the FGDs. Each FGD lasted between forty five minutes and two hours. These could have lasted longer but the strict high school timetables limited them to two hours.

\section{In-depth Interviews}

According to Nachmias and Nachmias (1996) "the personal interview is a face-to-face, interpersonal role situation in which an interviewer asks respondents questions designed to elicit answers pertinent to the research hypotheses" (Nachmias \& Nachmias (1996, p. 232). This study employed In-depth interview as a final data collection method. Interviews are advantageous in the sense that questions that were not clearly dealt with in questionnaires can be elaborated further. These were administered to purposively selected informants from FGD responses. These also constituted respondents selected from questionnaire responses based on the first three questions. These included, (a) whether the respondent belonged to a social network site(s), (b) the number of social network sites they belonged to, and (c) how often they accessed their social network site(s). Interview participants were purposively selected from respondents who belonged to SNSs, those who belonged to the highest number of SNSs, and those who had the highest frequency of accessing their SNSs within each class. The study, therefore, comprised four In-depth interviews drawn from a sample of one participant each from boys', girls', and two from mixed schools. Overall, two males and two females participated in the interviews. These were drawn from forms two, three and four. Each interview was conducted with the help of a research assistant who controlled the recording. The sessions, which lasted between 45 minutes to one and a half hours, were conducted in a quiet setting away from any interference.

\section{Data analysis and presentation}


Data analysis in mixed methods research relates to the type of research strategy chosen (Creswell, 2009). Collected data was organized using the following procedures, (a) collected data was pre-processed before analysis. The primary purpose of pre-processing is "to correct problems that are identified in the raw data" (Kombo \& Tromp, 2009, p. 11). These include differences between the results obtained by different interviewers. This stage entailed the elimination of unusable data, interpretation of ambiguous answers, and contradictory data from related questions, (b) development of a coding scheme. A coding scheme is defined as "an ambiguous set of prescriptions of how all possible answers are to be treated, and what (if any) numerical codes are to be assigned to particular responses" (Kombo \& Tromp, 2009, p. 111). Lastly, (c) data was stored in both paper and electronic forms. Quantitative data was analyzed with the aid of SPSS where the study hypotheses were tested using the t-test. Group comparisons were done using univariate analysis of variance (ANOVA). Qualitative data was coded then classified into themes, before construction of narratives.

\section{Results and discussion}

Comparatively, the means of each variable revealed that overall, high school teenagers' engagement on SNSs was mainly influenced by the need to gain social capital $(\mathrm{M}=3.7592, \mathrm{SD}=$ 0.49901), where most respondents specifically bridged social capital $(\mathrm{M}=4.0394, \mathrm{SD}=0.59548)$ through their choice of SNSs. To determine the degree of relationship between the explanatory variables, Pearson's Correlation was performed. Pearson's Correlation (r) is a measure of the strength of the association between two variables. This enabled the study to establish the level to which one variable moved together with the other in explaining engagement on social network sites (SNSs). Findings indicate that the relationship between all the variables, that is, surveillance, identity, and social capital with each other is significant since at significance level of 5 percent and 95 percent confidence level, two tail test is 0.01 . The highest correlation was found between surveillance and personal identity with a coefficient factor of $\mathrm{r}=0.469, \mathrm{p}<0.001$. Other significant levels included surveillance and diversion with a coefficient factor of $\mathrm{r}=0.381, \mathrm{p}<0.001$, personal identity and social capital with a coefficient factor of $\mathrm{r}=0.369, \mathrm{p}<0.001$, and surveillance and social capital with a coefficient factor of $\mathrm{r}=0.360, \mathrm{p}<0.001$. These findings indicate that high school teenagers who sought surveillance in their engagement on SNSs equally went for personal identity. This demonstrates the fact that personal identity correlated well with surveillance in the sense that high school teenagers who surveyed their surroundings identified the ideal or acceptable identities, which they preferably modeled through their chosen SNSs.

The $t$-test was used in this study to test hypotheses and determine whether the four independent variables influenced high school teenagers' choice of SNSs.

$$
\mathrm{H}_{\mathrm{o}}: \mu=3.4
$$

Versus $\mathrm{H}_{1}: \mu>3.4$

The $t$-test findings are represented in Table 1.0 and explained under each objective.

Table 1.0 One sample $t$-test scores

\begin{tabular}{ccccc}
\hline & \multicolumn{4}{c}{ Test Value $=3.4$} \\
\hline & Df & Sig. (2- & Mean & 95\% Confidence \\
tailed) & Difference & $\begin{array}{c}\text { Interval of the } \\
\text { Difference }\end{array}$ \\
\hline
\end{tabular}




\begin{tabular}{lrrrrrr} 
& & & & & Lower & Upper \\
& & & & & & \\
\cline { 6 - 8 } IDENTITY & 5.942 & 359 & $<0.001$ & 0.25463 & 0.1704 & 0.3389 \\
S/CAPITAL & 13.735 & 363 & $<0.001$ & 0.35924 & 0.3078 & 0.4107 \\
BONDING & 1.126 & 362 & 0.261 & 0.04793 & -0.0358 & 0.1316 \\
BRIDGING & 20.485 & 363 & $<0.001$ & 0.63938 & 0.5780 & 0.7008 \\
MAINTAINING & 11.907 & 360 & $<0.001$ & 0.39654 & 0.3310 & 0.4620 \\
\hline
\end{tabular}

\section{Influence of personal identity on choice of social network sites}

The first objective of this article sought to investigate the influence of personal identity on high school teenagers' choice of social network sites. This was measured using five Likert scale items. Findings revealed that high school teenagers sought to present their ideal image through SNSs $(\mathrm{M}=3.9944, \mathrm{SD}=1.08205)$. Each statement in this item posted a high mean $(>3)$ implying that personal identity rated highly in influencing the choice of SNSs. This is shown in Table 2.0.

Table 2.0 Influence of personal identity

\begin{tabular}{lllllllll}
\hline & SD & $\mathrm{D}$ & $\mathrm{N}$ & $\mathrm{A}$ & $\mathrm{SA}$ & & \\
& & $\%$ & $\%$ & $\%$ & $\%$ & $\%$ & Mean & $\begin{array}{l}\text { Std. } \\
\text { Deviation }\end{array}$ \\
\cline { 2 - 8 } & & & & & & & & \\
& & & 10.3 & 19.8 & 39.6 & 23.4 & 3.6212 & 1.15367 \\
$\begin{array}{l}\text { Social network sites allow other } \\
\text { people to understand who I am }\end{array}$ & 7 & & & & & & \\
$\begin{array}{l}\text { I try to make my profile represent } \\
\text { the kind of person I am }\end{array}$ & 4.5 & 6.7 & 11.7 & 39.1 & 38 & 3.9944 & 1.08205 \\
$\begin{array}{l}\text { I like to see how other people react } \\
\text { to my profile }\end{array}$ & 3.7 & 8.7 & 14.3 & 39 & 34.3 & 3.9157 & 1.07660 \\
$\begin{array}{l}\text { I cannot adjust my profile based on } \\
\text { how other people react to it }\end{array}$ & 14.3 & 15.4 & 19 & 25.2 & 26.1 & 3.3333 & 1.38342 \\
$\begin{array}{l}\text { I put a lot of effort into my social } \\
\text { network site profile }\end{array}$ & 15.3 & 19.2 & 24 & 22.3 & 19.2 & 3.1086 & 1.33785 \\
\hline
\end{tabular}

\section{One sample t-test for personal identity}

Considering that the hypothesis being tested was,

$\mathrm{H}_{01} \quad$ There is no relationship between personal identity and choice of social network sites among high school teenagers.

Personal identity equally yielded the following findings. Since $t(359)=5.942, \mathrm{p}<0.001$, we reject the null hypothesis and conclude that $\mu>3.4$, which implies that the mean score of personal identity index is above the neutral position meaning that respondents' choice of social network sites is determined by personal identity. This is illustrated in Table 1.0. Qualitative findings were not far from the quantitative in the sense that FGD and interview responses concurred with these findings. Participants were asked.

FGD QB (i) 1: Would you create a suitable identity on a SNS? 
Participant 1: To cover your real identity... for example if you have a person who likes bothering you... like Facebook is full of lies...people are full of lies. You know I am in Form 2 but on Facebook I could say I am in university. Everyone lies... why should you say the truth?... Even you should join the group. They can never catch you... they don't know you.

Participant 2: Because there are some parents who do not want to see their children on Facebook and you you want to join so you just create an identity that is not your own... maybe you put your own things...now your parents won't know you... whether you are on Facebook or not. My parents would just know I am just there and not on social network sites.

What if your parents were on SNSs? We would definitely block them. What if they fake their identity? ... as in we never just accept friendships from anyone. I would first engage potential friends through direct messaging before I accept their friend request.

Participant 3: The best thing is that you should not just trust everyone on SNSs. Others would post things that are not from them... like for me I would easily post something that my friends will not identify with me.

Interview QB (i) 2: How would you want your friends to see you online?

Participant: I would want to be seen as popular, fashionable; creative...you put a picture that would capture attention. You would want to make your friends believe that everything is going right in your life.

Personal identity influenced high school teenagers' choice of social network sites $(t(359)=5.942$, p $<0.001)$. This is in agreement with Dunne and Lawlor (2010) and Chigona, Kamkwenda and Manjoo (2008) who found that personal identity determined the choice of social network sites. Although none of their studies focused on high school teenagers, this could be considered a first step in determining high school teenagers' SNSs preferences. Harrison and Thomas (2009) attest to the fact that the popularity of SNSs such as Facebook, MySpace and LinkedIn demonstrate the addictive appeal of online and virtual communities across generations and cultures, particularly to teenagers. These findings are in tandem with Boyd's (2008) argument that "teens are modeling identity through social network profiles so that they can write themselves and their community into being" (p. 120). Dunne and Lawlor (2010) equally alluded to active uses of SNSs among the youth to personal motives and gratifications in terms of presenting and managing certain identity and persona in a social context. These findings also concur with Chigona, Kamkwenda and Manjoo (2008) who argued that among the process gratifications sought by the youth included the need for image, fashion and status.

\section{Influence of social capital on choice of social network sites}

In order to examine the influence of social capital on high school teenagers' SNS preferences, the study adopted William's social capital scale. This was modified to suit the present context. Aspects of bonding, bridging, and maintaining social capital were measured using 15 Likert scale statements to which respondents were supposed to agree, strongly agree, neutral, disagree and strongly disagree. The means and standard deviations for bonding social capital are represented in Table 3.0.

Table 3.0 Influence of bonding social capital 


\begin{tabular}{|c|c|c|c|c|c|c|c|}
\hline & SD & $\mathrm{D}$ & $\mathrm{N}$ & $\mathrm{A}$ & SA & & \\
\hline & $\%$ & $\%$ & $\%$ & $\%$ & $\%$ & M & SD \\
\hline $\begin{array}{l}\text { There are several people on } \\
\text { social network sites I trust to } \\
\text { help solve my problems }\end{array}$ & $\begin{array}{l}15 . \\
9\end{array}$ & 14.8 & $\begin{array}{l}23 . \\
1\end{array}$ & 30.4 & 15.9 & 3.1560 & 1.30455 \\
\hline $\begin{array}{l}\text { There is someone on social } \\
\text { network sites I can turn to for } \\
\text { advice about making very } \\
\text { important decisions }\end{array}$ & $\begin{array}{l}12 . \\
7\end{array}$ & 11.6 & $\begin{array}{l}12 . \\
4\end{array}$ & 38.4 & 24.9 & 3.5110 & 1.32152 \\
\hline $\begin{array}{l}\text { There is no one on social } \\
\text { network sites that I feel } \\
\text { comfortable talking to about } \\
\text { intimate personal problems }\end{array}$ & $\begin{array}{l}13 . \\
8\end{array}$ & 13.3 & $\begin{array}{l}17 . \\
7\end{array}$ & 34 & 21.3 & 3.3564 & 1.32422 \\
\hline $\begin{array}{l}\text { When I feel lonely, there is no } \\
\text { one on social network sites I } \\
\text { can talk to }\end{array}$ & 7.7 & 7.7 & 6.6 & 33.3 & 44.6 & 3.9945 & 1.23260 \\
\hline $\begin{array}{l}\text { If I need an emergency loan of } \\
100 \text { bob, I know someone on } \\
\text { social network sites I can talk } \\
\text { to }\end{array}$ & $\begin{array}{l}19 . \\
1\end{array}$ & 15 & $\begin{array}{l}11 . \\
9\end{array}$ & 31.9 & 22.2 & 3.2299 & 1.43944 \\
\hline
\end{tabular}

The five Likert scale items presented to test whether high school teenagers sought to bond social capital through their choice of SNSs returned interesting findings. High school teenagers tended to turn to SNSs most when lonely $(\mathrm{M}=3.9945)$ and least trusted people on SNSs to help solve their problems $(\mathrm{M}=3.1560)$. Qualitative findings support this, where a key FGD participant commented:

Participant 3: The best thing is that you should not just trust everyone on SNSs. Others would post things that are not from them... like for me I would easily post something that my friends will not identify with me.

\section{Table 4.0 Influence of bridging social capital}

\begin{tabular}{lllllll}
$\mathrm{SD}$ & $\mathrm{D}$ & $\mathrm{N}$ & $\mathrm{A}$ & $\mathrm{SA}$ & & \\
$\%$ & $\%$ & $\%$ & $\%$ & $\%$ & Mean & $\begin{array}{l}\text { Std. } \\
\text { Deviation }\end{array}$ \\
\hline
\end{tabular}

Interacting with people on social network sites makes me less interested in things that happen outside of my

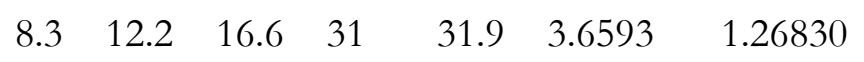
school. Interacting with people on social network sites makes me want to try new things.

$\begin{array}{lllllll}4.4 & 4.9 & 12.1 & 47.3 & 31.3 & 3.9615 & 1.01431\end{array}$

Interacting with people on social $\begin{array}{llllllll}\text { network sites makes me curious about } & 2.2 & 2.5 & 7.2 & 43.9 & 44.2 & 4.2541 & 0.86582\end{array}$ other places in the world. 
Interacting with people on social $\begin{array}{llllllll}\text { network sites makes me feel like part of } & 2.2 & 3.9 & 8.8 & 37.5 & 47.7 & 4.2452 & 0.92715\end{array}$ a larger community.

Interacting with people on social $\begin{array}{llllllll}\text { network sites makes me feel connected } & 3.9 & 3.3 & 16 & 33.9 & 43 & 4.0882 & 1.03152\end{array}$ to the bigger picture.

High school teenagers' interaction with people on SNSs made them curious about other places in the world $(\mathrm{M}=4.2541)$. Equally, interacting with people on SNSs made them feel like a part of a larger community $(M=4.2452)$. Respondents strongly agreed with the statements in this section as demonstrated by the means in Table 4.0.

Table 5.0 Influence of maintaining social capital

\begin{tabular}{lllllll}
$\mathrm{SD}$ & $\mathrm{D}$ & $\mathrm{N}$ & $\mathrm{A}$ & $\mathrm{SA}$ & & \\
$\%$ & $\%$ & $\%$ & $\%$ & $\%$ & Mean & $\begin{array}{l}\text { Std. } \\
\text { Deviation }\end{array}$ \\
\hline
\end{tabular}

I'd be able to find out about events in another school from a high school friend studying there. If I needed to, I could ask a high school friend to do a small favor for me.

I would be able to find information about college or work opportunities from a high $\begin{array}{lllllll}2.8 & 4.7 & 7.8 & 49.6 & 35.1 & 4.0947 & 0.92872\end{array}$

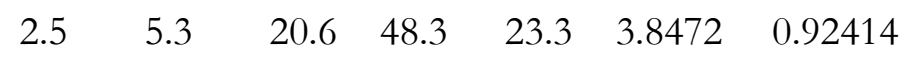
school friend.

It would not be easy to find $\begin{array}{llllllllll}\text { people to invite to my high } & 10.9 & 11.1 & 13.9 & 27.9 & 36.2 & 3.6741 & 1.35043\end{array}$ school leavers bash.

Respondents were given a set of statements to test whether their choice of SNSs was influenced by the need to maintain social capital. Findings indicate that respondents would be able to find out about events in other schools from their peers studying there $(\mathrm{M}=4.0947, \mathrm{SD}=$ 0.92872). Comparatively, each Likert item scored a high mean indicating that high school teenagers' choice of SNSs was influenced by maintaining social capital. This is illustrated in Table 5.0. The fifth Likert scale item "I'd be able to stay with a high school friend if I travelled to a different town" was eliminated after posting a low mean $(<2)$. This indicated that it did not significantly affect choice of SNSs.

\section{One sample $t$-test for social capital}

To test the hypothesis,

$\mathrm{H}_{02}$ There is no relationship between social capital and choice of social network sites among high school teenagers. 
As illustrated in Table 1.0, one sample $t$-test finding revealed that social capital is a determining factor for social network sites choice since $t(363)=13.735, \mathrm{p}<0.001$, we reject the null hypothesis and conclude the $\mu>3.4$, which implies that the mean score of social capital index is above the neutral position meaning that there is a relationship between social capital and choice of social network sites among high school teenagers. Based on qualitative responses, social capital equally emerged as a key theme in high school teenagers' SNSs preferences. Participants were emphatic about their motivations for choosing specific SNSs as illustrated.

Probing question: How do you connect with your primary school friends who might have joined different schools?

Participant 1: We usually connect like in Facebook... you can connect through the 'people you may know' feature where you can see your friend's pictures, then you add them and can contact them.

FGD QB (ii) 2: Would you accept an invite from a stranger on your SNS?

Participant 6: No...It depends. Another boy has ever told me that we meet. This was on Facebook. We agreed to meet in a place in town...then like when I reached the venue before him I asked how far he had reached... and he was like, even me I am in the same restaurant... so when I called him I realized he was standing somewhere there and then I told him to wave from wherever he was... so when I just looked and saw him I said no no... I have never met such a person. I walked out without even interacting with bim.

This clearly illustrates the urge to bond social capital among teenagers through establishment of new bonds with strangers but equally raises the question of the negative aspects of SNSs such as exploitation.

Social capital, therefore, plays an important role in determining high school teenagers' SNSs preferences $(t(363)=13.735, \mathrm{p}<0.001)$. This echoes Valenzuela, Park and Kee (2009) who argued that investment in social networks enabled individuals to develop norms of trust and reciprocity, which are necessary in collective activities. These activities may vary among high school teenagers. Considering that the core idea of social capital is the resources available to people through their social interactions, Valenzuela et al. (2009) further posit that when researchers operationalize Internet use as time spent with the technology, they ignore the multiple audiences' motives and experiences that the medium allows. As evidenced in the study findings, high school teenagers tend to bridge and maintain social capital more than bonding. Valenzuela et al. (2009) contend that weak tie networks produce bridging social capital because they connect people from different life situations. "Individuals in weak tie relationships do not gain the benefits of bonding social capital, such as emotional support that occurs based on the interdependence and commonalities of strong tie networks" (Valenzuela et al., 2009: p. 879). This is exhibited in the fact that two Likert scale items for bonding social capital scored low means $(<3.4)$. These statements include; "there are several people on social network sites I trust to help solve my problems" $(\mathrm{M}=3.1560, \mathrm{SD}=1.30455)$, and "if I need an emergency loan of 100 bob, I know someone on social network sites I can talk to" (M $=3.2299$, $\mathrm{SD}=1.43944)$. Overall, high school teenagers bonded existing relationships through their online interactions and equally sought to maintain existing relationships through their choice of social network sites. This in essence supported the argument by Valenzuela et al. (2009) that individuals with a large and diverse network of contacts are thought to have more social capital than 
individuals with small, less diverse networks. Considering the diversity of the school system, this could not be further from the truth.

\section{Relating the Uses and Gratifications (U\&G) approach}

This study adopted the U\&G theory. This approach focuses on the consumer rather than the message. In the case of this study the assumption is that the focus is on the high school teenager rather than the media messages sent and received through SNSs. These teenagers are assumed to be active and goal directed. This is evidenced in the study findings by the three gratification factors of personal identity, surveillance and social capital, which emerged as the main gratifications sought by high school teenagers. These teenagers eventually choose specific SNSs in order to fulfill their own needs. The media are considered to be only one factor contributing to how needs or high school teenagers' gratifications get met, and the teenagers in essence know their needs and how to gratify these needs. This is through their choice of SNSs. Based on the study findings, the U\&G theory can, therefore, be contextualized to read that, (a) high school teenagers have social and psychological needs, which (b) determine the gratifications sought through choice of SNSs and (c) have expectations of the different SNSs available, which (d) enables them to choose specific SNSs, and (e) engage in different online activities, resulting in ( $\mathrm{f}$ ) gratifications obtained $(\mathrm{GO})$ and $(\mathrm{g})$ other consequences, both positive and negative, mostly unintended.

\section{Conclusion}

Our findings on personal identity corroborate previous studies by Boyd (2008) and Dunne and Lawlor (2010) who attributed the use of SNSs among the youth to personal identity. Chigona, Kamkwenda and Manjoo (2008) also agreed that the youth were motivated by the need for image, fashion and status in their SNSs use. This could have both positive and negative impacts considering aspects such as sexting, cyber bullying and even human trafficking. Positively, these identities could cultivate good relationships, which can improve their performance in school and enhance sexual health, awareness of the dangers of illicit drugs and sexually transmitted diseases. The fact that most teenagers would present an "ideal" identity online shows that there is an identity crisis in this age group. Equally, these teenagers seek acceptance among their peers and thus switch their identities depending on which peer group they would feel "cool" belonging to. Among the features presented on online SNSs, Facebook presented the best alternative for teenagers to find acceptance in their personal profiles. The fact that one can "Like" another person's status update including photos and status messages supports the popularity of Facebook among this group. Other SNSs such as Twitter, LinkedIn, Google+, and Pinterest could borrow a leaf from this and improve their interactivity. Equally, qualitative findings on social capital pointed to bridging social capital as a motivation for SNSs choice among teenagers. These findings are in line with Valenzuela et al. (2009) who contended that weak tie networks produced bridging social capital because they connected people from different life situations. This could be attributed to the fact that a significant percentage $(38.7 \%)$ belonged to form two and were in the process of bridging their relationships with those that had completed primary level exams (class 8) and were waiting to join form one. This particular group equally strove to maintain social capital in the sense that the newly established friendships in high school had to be maintained.

In this article, we provide some of the first clear evidence of the influence of user gratification factors of social capital and personal identity on high school teenagers' choice of social network sites in Kenya. It is, moreover, one of the first large scale demonstrations that a mixed 
methodology design can be deployed to estimate the causal impact of user gratifications on SNSs choice. Based on the foregoing summary, it is, therefore, worth concluding that indeed the choice of social network sites is a complex phenomenon. Whereas the set objectives were fulfilled, there still exist gaps in understanding user motivations for SNSs usage among high school teenagers. We, therefore, conclude that the high percentage of high school teenagers belonging to SNSs is a clear indication of the importance that this category of youths attaches to this medium. The appeal of SNSs to adolescent teenagers should be encouraged and probably harnessed for positive outcomes both socially and in academics.

\section{Recommendations and suggestions for future research}

The use of mixed method designs in research, especially in developing countries is underutilized. This is evidenced by empirical literature presented in this study. Based on Johnson, Onwuegbuzie and Turners' (2007) argument, mixed method research provided rich data for this study. Johnson et al. (2007) further admit that this research design offers a powerful third paradigm choice that often will provide the most informative, complete, balanced, and useful research results. More studies should be conducted using the mixed method design in order to strengthen this as an emerging approach in mass communication research. This will in the long run enrich the area of mass communication through more comprehensive and detailed research, especially in developing countries, which is lacking. With the emergence of new media technologies, mass communication researchers need to rethink the use of traditional research designs, which might not necessarily be able to capture the realities on the ground.

Behavior change campaigns targeting teenagers and the youth in general require reengineered thinking. The positive and negative outcomes of SNSs usage point to an emerging need to positively harness the power of SNSs in behavior change campaigns. The fact that a significant percentage of the youth belong to social network sites is testimony to the emerging importance of this medium. Behavior change campaigners should enhance the utilization of social network sites as a medium for communicating with teenagers. This is through the development of applications that will directly target the needs of teenagers. These could be one stop shops for information regarding sexual health, the dangers of drug addiction and alcoholism, and the negative impact of youth radicalization in society.

Considering that a majority of teenagers are spending a considerable amount of time on SNSs daily, and that these interactions are mainly occurring through Internet enabled mobile phones, policy makers within government and the relevant ministries need to take keen interest in the upsurge of SNSs and high school teenagers' interactions with these media. Recent reports of youth recruitment into terror cells by insurgent groups should redirect government efforts to the workings of SNSs and the motivations for teenagers choosing specific SNSs. This will enable the government and key stakeholders to identify the gratifications sought and mitigate in obtaining these gratifications through positive use of SNSs.

Development of computer software and applications for mobile phones and computers should consider the user needs of developing countries. As it stands, the five most popular social network sites are a creation of Western countries, therefore, making teenagers from developing countries net consumers rather than creators of content. Efforts should be put in place to encourage teenagers in developing countries to help in the creation of software applications necessary to run contextualized SNSs. These could capture neglected areas such as local languages.

We, additionally, suggest further research in the following contexts. (1) This study only focused on Nairobi County. Further studies could be carried out in rural counties. Comparative studies could equally be done on both urban and rural counties to establish whether gratifications 
factors will vary, and (2) considering that the youth constitute a wider age bracket than the teenage segment, which was the focus of this study, further studies could be carried out with a widened age bracket to cover the youth.

\section{REFERENCES}

Ahn, J. (2011). The effects of social network sites on adolescents' social and academic development: Current theories and controversies. Journal of the American Society for Information Science and Technology, 62(8), 1435-1445.

Baker, R. K., \& White, K. M. (2010). Predicting adolescents' use of social networking sites from an extended theory of planned behavior perspective. Computers in Human Behavior, 26(6), 15911597.

Boyd, M. D., \& Ellison, B. N. (2008). Social network sites: Definition, history, and scholarship. Journal of Computer-Mediated Communication, 13, 210-230.

Brandtzæg, P. B., \& Heim, J. (2009). Why people use social network sites. Online Communities, LNCS 5621, 143-152.

Chigona, W., Kamkwenda, G., \& Manjoo, S. (2008). Uses and gratifications of mobile internet among South African students. Interworld Communications, 10(3).

Creswell, J. W. (2009). Research design: Qualitative, quantitative, and mixed methods approaches (3rd ed.). Los Angeles: Sage Publications.

Dunne, A., Lawlor, M., \& Rowley, J. (2010). Young people's use of online social networking sites - a uses and gratifications perspective. Journal of Research in Interactive Marketing, 4(1), 46-58.

Ellison, N. B., Steinfield, C., \& Lampe, C. (2007). The benefits of Facebook "Friends:” Social capital and college students' use of online social network sites. Journal of Computer-Mediated Communication, 12, 1143-1168.

Fawkes, J., \& Gregory, A. (2001). Applying communication theories to the Internet. Journal of Communication Management, 5(2), 109-124.

Greenhow, C., \& Robelia, B. (2009). Old communication, new literacies: Social network sites as social learning resources. Journal of Computer-Mediated Communication, 14, 1130-1161.

Harrison, R., \& Thomas, M. (2009). Identity in online communities: social networking sites and language learning. International Journal of Emerging Technologies and Society. 7(2), 109-124.

Heaven, C. \& Tubridy, M. (2007). Global youth culture and youth identity. Retrieved from http://www.verina.vesel.info/wp-content/uploads/2007/11/youth_culture1.pdf

Hennink, M., Hutter, I., \& Bailey, A. (2011). Qualitative research methods. Los Angeles: Sage publications.

Joinson, A. N. (2008). 'Looking at', ‘looking up' or 'keeping up with' people? Motives and uses of Facebook. CHI 2008 Proceedings, April 5-10, 2008. Florence, Italy, 1027-1036.

Njonjo, K. S., \& Mwangola, M. (2011). Kenya Youth Scenarios. Nairobi: Institute of Economic Affairs (IEA).

Katz, E., Blumler, J. G., \& Gurevitch, M. (Winter, 1973-1974). The Public Opinion Quarterly, 37(4), 509-523.

Kenya National Bureau of Statistics (KNBS) \& ICF Macro. (2010). Kenya demographic and health survey 2008-09. Calverton, Maryland: KNBS and ICF Macro.

Kombo, D. K., \& Tromp, L. A. (2009). Proposal and thesis writing: An introduction. Nairobi: Paulines publications Africa.

Larose, R., Mastro, D., \& Eastin, M. (2001). Understanding internet usage: A social- cognitive approach to uses and gratifications. Social Science Computer Review, 19, 395. 
Lee, M., \& McKinney, J. (2013). Understanding and applying research design. New Jersey: John Wiley and Sons, Inc. Retrieved from http://ebrary.com/lib/kmethke/docDetail.action

Ministy of Youth Affairs. (2007). The national youth policy. Nairobi: Government of Kenya Press.

Nachmias, C. F., \& Nachmias, D. (1996). Research methods in the social sciences (5th ed.). London: Hodder Education.

Onwuegbuzie, A., \& Collins, K. (2007). A typology of mixed methods sampling designs in social science research. The Qualitative Report, 12(2), 281- 316.

Papacharissi, Z., \& Mendelson, A. (2008). Towards a new(er) sociability: Uses and gratifications, and social capital on Facebook. Paper presented at the Internet Research Conference, Copenhagen, Denmark, October, 2008.

Quan-Haase, A., \& Young, A. L. (2010). Uses and gratifications of social media: A comparison of Facebook and Instant Messaging. Bulletin of Science Technology and Society, 30, 350-361.

Song, I., Larose, R., Eastin, M., \& Lin, C. (2004). Internet Gratifications and Internet Addiction: On the Uses and Abuses of New Media. Cyber Psychology and Behavior, 7(4), 384-394.

Subrahmanyam, K., Reich, S. M., Waechter, N., \& Espinoza, G. (2008). Online and offline social networks: Use of social networking sites by emerging adults. Journal of Applied Developmental Psychology, 29, 420-433.

Tayie, S. (2005). Research methods and writing research proposals. Cairo: Centre for Advancement of Postgraduate Studies and Research in Engineering Sciences.

UNESCO. (2006). World data on education. ( $6^{\text {th }}$ Ed.). Retrieved from www.ibe.unesco.org/countries/WDE/2006/subsaharan Africa/.../Kenya.pdf

UNFPA. (2011). State of World population 2011: People and possibilities in a world of 7 billion. New York: UNFPA.

Urista, M. A., Dong, Q., \& Day, K. D. (2009). Explaining why young adults use MySpace and Facebook through uses and gratifications theory. Human Communication, 12(2), 215-229.

Valenzuela, S., Park, N., \& Kee, F. K. (2009). Is there social capital in a social network site? Facebook use and college students' life satisfaction, trust, and participation. Journal of Computer-Mediated Communication, 14, 875-901.

Williams, D. (2006). On and off the 'Net: Scales for social capital in an online era. Journal of Computer-Mediated Communication, 11, 593-628.

Wyche, S. P., Schoenebeck, Y. S., \& Forte, A. (2013). "Facebook is a luxury": An exploratory study of social media use in rural Kenya. CSCW, 2013, February 23-27. 